\title{
Improved Control Strategy for Grid Connected Scheme Based on PV Array and Wind-driven Induction Generators
}

\author{
P. Sivakumar ${ }^{1}$, M. Arutchelvi ${ }^{2}$ and R. Soundarapandian ${ }^{3}$ \\ IJ College of Engineering and Technology, India; Ipssivakumar@gmail.com \\ 2Saranath College of Engineering, India; arutchelvi@gmail.com \\ ${ }^{3}$ AMET University, India; rsoundar88@gmail.com
}

\begin{abstract}
Grid connected distributed generators are becoming increasingly popular owing to their reliability. In earlier days, one of the drawbacks in the solar energy sources is the need for energy storage for the system to be utilized for a significant percentage of the day. One way of overcome this disadvantages by utilizing the inverter and its controller circuits for PV based DG units during the day and night times for improving the reactive power compensation and harmonic elimination on its neighboring DG units and the grid by proper exchange of reactive power between the sources. The existing Proportional-Integral controller (PI) and predictive control methods are more dominant in current error compensation. But the conventional type PI controllers normally do not have appropriate compensation from the inverters for the grid connected applications. In this paper a composite controller design comprising of both voltage oriented control and direct power control is developed for the grid side control. The control strategy is based on generation of current reference for current controller by utilizing the separated fundamental component of power to meet the instantaneous power demand at PCC and the power availability at PV sourced inverter. The state space model for the entire scheme is presented and used for simulation. Comprehensive analysis and simulation of the scheme with variations in irradiation, wind speed and customer loads have been presented in this work. The analysis of the scheme for non linear load and three phase fault at PCC for hybrid scheme with PV array and wind generator has been attempted for the first time in this work. The adaptability of proposed controller to work in islanded mode has also been tested. The simulations have been carried out for all these variations and compared with the direct power control and the significance of the proposed work is presented.
\end{abstract}

Keywords: Composite Power Control, Direct Power Control, Induction Generator, Nonlinear Load, Photovoltaic Inverter, Voltage Oriented Control

$i_{\text {wds }}$ Stator d-axis current(A)

$i_{\text {wqs }}$ Stator q-axis current(A)

$i_{w d r-}$ Rotor d-axis current(A)

$i_{\text {war- }}$ Rotor $\mathrm{q}$-axis current(A)

$i_{w m d}$ magnetizing $\mathrm{d}$-axis current(A)

$i_{w m d}$ magnetizing $\mathrm{q}$-axis current(A)

$L_{m}$ magnetising inductance $(\mathrm{H})$

$L_{s} \quad$ stator leakage inductance $(\mathrm{H})$

$L_{r} \quad$ rotor leakage inductance $(\mathrm{H})$

$\omega$ angular speed of the space vector $(\mathrm{rad} / \mathrm{s})$

$\omega_{r}$ electrical rotor angular speed, $(\mathrm{rad} / \mathrm{s})$

$C_{e f}$ effective virtual capacitance

\section{Nomenclature}

$i_{p v} \quad$ PV array current(A)

$i_{i p v} \quad$ current supplied from the PV source to inverter(A)

$P_{i} \quad$ Real power supplied from the PV sourced Inverter (W)

$Q_{i}$ Reactive power supplied from the PV sourced Inverter (Var)

$P_{w}$ Real power supplied from the Induction generator (W)

$Q_{w}$ Reactive power absorbed by the Induction generator (Var)

$P_{L} \quad$ Real power absorbed by the load connected to the PCC (W)

$Q_{L}$ Reactive absorbed by the load connected to the PCC (Var)

$P_{g}$ Grid Real power (W)

$i_{L f}^{g}$ fundamental component of load current of (A)

$i_{\text {Lnf }}$ non-fundamental component of load current of (A)

$v_{g}$ grid voltage at $\mathrm{PCC}(\mathrm{V})$

*Author for correspondence 


\section{Introduction}

In recent years there has been a growing interest in moving away from large centralized power generation towards distributed generators (DG). Wind and solar powers are most promising clean energy sources since it can easily be captured by wind generators and Photovoltaic (PV) array with high power capacity. Both these resources exhibit complementary behavior and can be well utilized as hybrid distributed generators to offer higher reliability ${ }^{1,2}$ for autonomous and grid connected applications. These resources can be integrated to utility grid which results in peak saving and reduction in maximum power demand.

In this paper such development of a controller structure for a grid integrated hybrid scheme based on these two resources is taken up. Investigations are carried out for feeding customer loads and feed excess power to grid and also to supply the customer demand in the event of grid failure. However when Induction Generators (IG) are used for such applications, they consume reactive power which is a matter of concern for such applications ${ }^{3}$. Further more several non linear loads are connected at Point of Common Coupling (PCC) ${ }^{4}$. The controller has been so designed in such a way that PV sourced Voltage Source Inverter (VSI) provides the required reactive power and compensating harmonic currents to regulate the terminal voltage profile at PCC under various loading conditions with help of effective exchange of reactive power ${ }^{5}$. The controller design for such VSI must meet the power balance at PCC.

The most commonly adopted for grid integrated control includes Voltage Oriented Control (VOC) and Direct Power Control (DPC) ${ }^{6,7}$. VOC is the most popular and effectively used strategy with high dynamics and good performance. However one of the most important disadvantages of VOC is the necessity of having a large ratio between the switching and grid frequency to model the converter as an ideal continuous voltage source $^{8,9}$. Furthermore, the VOC requires a coordinate transformation between $\mathrm{abc}$ and dq0 frame, that leads to coupling effects between transformed variables and more complex algorithm. On the other hand, the DPC strategy does not involve complicated computation and ensures speed in the response of power flow between the source and the grid but the drawback is the variable switching frequency. The existing works either use DPC or VOC and predictive control methods for current error compensation. However these predictive controllers normally do not have appropriate compensation from the inverters for the grid connected applications. The existing predictive control algorithms based on deadbeat control are employed in VSI for both power and voltage control.

Digital predictive control strategies are quite complex and suffer from control delay. Moreover, these controllers use the dc link voltage as one of the control parameter and this method is not found suitable for PV based DG units without dc-dc converters. Further, investigations on gridconnected hybrid wind-driven IG and PV scheme with non linear loads at PCC have not taken up so far and one such scheme is investigated in this paper. To accomplish this, a new Composite Power Controller (CPC) comprising of both VOC and DPC is developed for the grid side control. Comprehensive analysis of the scheme with variations in irradiation, wind speed and customer loads are taken up in this work. The block schematic for the hybrid grid connected DG system based on PV sourced.

\section{Description of the Scheme}

Inverter and wind driven IG with the proposed control is indicated in the Figure 1. The Photovoltaic array sourced

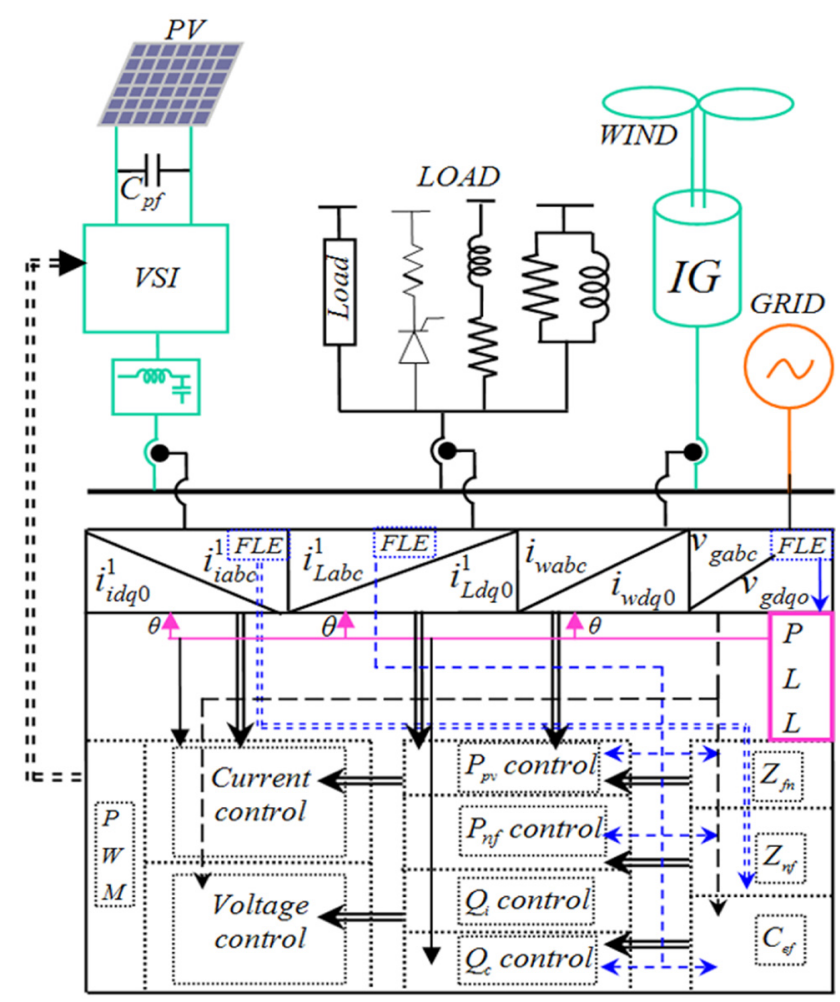

Figure 1. Functional block schematic of proposed system 
inverter is connected with the utility grid through LC filter and the wind driven IG is integrated to the grid at PCC. Switching capacitor is connected in parallel with induction generator at PCC for partial reactive power compensation to the IG. The consumer load comprises of loads like linear, nonlinear, dynamic and static loads are connected to PCC. The proposed controller is a composite controller comprising of VOC and DPC to control the firing pulses to the PV sourced inverter. DPC comprises of power controller for real and reactive power computation and control. The Fundamental Extractor (FLE) is used to extract the fundamental component from measured superimposed power signals from PCC. The non-fundamental components of the power signal thus separated are utilized for estimating non-fundamental power reference value of PV sourced inverter. The Phase Lock Loop (PLL) block is used to generate theta value for abc to dq0 transformation and there by computes the instantaneous impedance values of $Z_{f n}$ (impedance due to fundamental components) and $Z_{n f}$ (impedance due to non fundamental components) of the loads from the measured signal. These impedance values are used for effective capacitance $C_{e f}$ evaluation for generating reactive power reference value of VSI. The voltage control block generates current reference value for current control block and the output of this block generates voltage magnitude and angle for the modulating signals for sine pulse width modulation (SPWM). Using these modulating signals, the firing pulses are generated for VSI.

\section{Modelling of the Proposed Scheme}

\subsection{Grid Connected Induction Generator Model}

The $d q$ model of the induction generator connected to the utility grid as in ${ }^{10}$ is modified to include the equivalent capacitor for incorporating load variation,

$$
\begin{aligned}
v_{g d}= & R_{S} i_{w d s}+\rho L_{s} i_{d s}+\frac{1}{\rho C_{e f}} i_{w d s}-\omega_{r} L_{s} i_{w q s} \\
& -\omega L_{m} i_{w q r}+\rho L_{m} i_{w d r} \\
v_{g q}= & R_{S} i_{w q s}+\rho L_{s} i_{w q s}+\frac{1}{\rho C_{e f}} i_{w q s}+\omega_{r} L_{s} i_{w d s} \\
& -\rho L_{m} i_{w q r}+\omega L_{m} i_{w d r}
\end{aligned}
$$

$$
\begin{aligned}
v_{d r}= & R_{r} i_{w d r}+\rho L i_{w d r}+\left(\omega_{r}-\omega\right) L_{r} i_{w q r} \\
& -\left(\omega_{r}-\omega\right) L_{m} i_{w q s}+\rho L_{m} i_{w d s} \\
v_{q r}= & R_{r} i_{w q r}+\rho L i_{w q r}+\left(\omega-\omega_{r}\right) L_{r} i_{w d r} \\
& -\left(\omega_{r}-\omega\right) L_{m} i_{w d s}+\rho L_{m} i_{w q s}
\end{aligned}
$$

The current through the equivalent capacitor is given by,

$$
\begin{aligned}
& i_{w c d}=C_{e f} \rho v_{g d} \\
& i_{w c q}=C_{e f} \rho v_{g q}
\end{aligned}
$$

Where $\rho=d / d t$

The mechanical system is represented as

$$
\begin{gathered}
\frac{d \omega_{r}}{d t}=\frac{1}{2 H}\left(T_{e}-F_{o r}-T_{m}\right) \\
T_{e}=-\left(\frac{3}{2}\right)\left(\frac{P_{w}}{2}\right) L_{m}\left(i_{w q s} i_{w d r}-i_{w d s} i_{w q r}\right)
\end{gathered}
$$

Where $T_{e}$ and $T_{m}$ represent the electromagnetic torque and mechanical shaft torque and taken negative for generator action.

\subsection{PV Sourced Grid Connected Inverter}

The equivalent circuit grid connected inverter is indicated in Figure 2. The resulting state space equation for the grid connected VSI is

$\left[\begin{array}{l}\frac{d i_{i d}}{d t} \\ \frac{d i_{i q}}{d t}\end{array}\right]=\frac{1}{L}\left[\left[\begin{array}{cc}-R & \omega L \\ -\omega L & -R\end{array}\right]\left[\begin{array}{c}i_{i d} \\ i_{i q}\end{array}\right]+\left[\begin{array}{c}v_{i d} \\ v_{i q}\end{array}\right]-\left[\begin{array}{c}v_{g d} \\ v_{g q}\end{array}\right]\right]$

The output of photovoltaic array is coupled to the inverter with appropriate control. The power delivered by Photovoltaic array parameters dynamically changes due to irradiation and temperature variation ${ }^{11}$. From the equivalent circuit, the PV array and inverter currents are calculated using equations (10)-(12) for regulating the

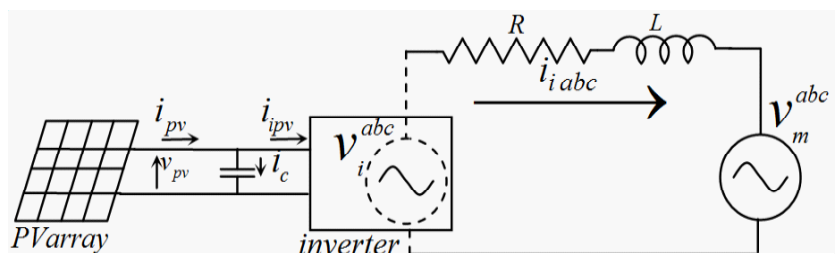

Figure 2. Simple equivalent model of PV sourced grid connected ..inverter 
PV sourced inverter power. State space power control model of PV sourced grid inverter as in $^{12}$ is

$$
\begin{gathered}
i_{p v}=i_{c}+i_{i p v} \\
i_{p v}=c \frac{d v_{p v}}{d t}+i_{i p v} \\
i_{p v}=c \frac{d v_{p v}}{d t}+\frac{3}{2}\left(k_{m} \cos \theta i_{i d}+k_{m} \sin \theta i_{i q}\right) \\
{\left[\begin{array}{c}
\dot{i_{i d}} \\
\dot{i_{i q}} \\
\dot{v_{p v}}
\end{array}\right]=\left[\begin{array}{cc}
-R / L & \frac{k_{m} v_{p v} \cos \theta}{L} \\
-\omega & \frac{k_{m} v_{p v} \sin \theta}{L} \\
-\frac{3}{2 c} k_{m} \cos \theta i_{i d} & -\frac{3}{2 c} k_{m} \sin \theta i_{i q} \\
\frac{1}{r c}
\end{array}\right]\left[\begin{array}{c}
i_{i d} \\
i_{i q} \\
v_{p v}
\end{array}\right]} \\
+\left[\begin{array}{cc}
\frac{1}{L} & 0 \\
0 & -\frac{1}{L} \\
0 & 0 \\
v_{g q}
\end{array}\right]\left[\begin{array}{l}
v_{g d} \\
v^{2}
\end{array}\right]
\end{gathered}
$$

\subsection{Nonlinear Load Model (Three Phase Rectifier Load Model)}

The nonlinear load comprising of a three-phase diode rectifier feeding an R-L load is modelled in $d q$ reference frame for analysis. The rms value of input currents $\left(i_{L 2 a}, i_{L 2 b}\right.$, and $\left.i_{L 2 c}\right)$ to the three-phase diode rectifier in $d q$ reference frame is given by,

$$
\left[\begin{array}{l}
i_{L 2 d} \\
i_{L 2 q}
\end{array}\right]=\left(\begin{array}{l}
a_{d} \\
a_{q}
\end{array}\right) i_{d c}
$$

where $i_{L 2 d}$ and $i_{L 2 q}$ are $d$ and $q$ axis of nonlinear load current. The current drawn by the three phase rectifier is directly convert $a b c$ to $d q o$ frame by using equation (14), in this equation the value of $a_{d}$ and $a_{q}$ is changed every $60^{\circ}$ of one cycle as shown in Table 1.

Table 1. Nonlinear load current in dq reference frame

\begin{tabular}{lcccccc}
\hline Mode & 1 & 2 & 3 & 4 & 5 & 6 \\
\hline$a_{\mathrm{d}}$ & $1 / \sqrt{ } 3$ & $-1 / \sqrt{ } 3$ & $-2 / \sqrt{ } 3$ & $2 / \sqrt{ } 3$ & $1 / \sqrt{ } 3$ & $-1 / \sqrt{ } 3$ \\
$a_{\mathrm{q}}$ & 1 & -1 & 0 & 0 & -1 & 1 \\
\hline
\end{tabular}

4. Modelling of Proposed Composite Controller for Hybrid Grid Integrated dg Sources

\subsection{Design and Development of Composite Controller}

The proposed controller consists of three control loops which includes voltage, current and power control loop. In existing VOC employed for grid connected VSI, the coupling term between the d-axis and q-axis is cancelled out by feed forward controllers. However, to improve the dynamic performance of the controller, the reference current for the current control in the proposed control is taken from the power control block for cancellation of the coupling effect and an attempt has been made to incorporate the dynamic load changes at PCC and filter drops across the inverter in the controller design. During fault at PCC, the grid angle at PCC varies and this effect is nullified by proper adjustment of non-fundamental impedance in the current controller.

\subsubsection{Voltage and Current Control Block}

Voltage and Current control block estimates the voltage and current reference for the inverter using equation. (11). Voltage control block gets the input reference signal from the power control block. The input to the current control block is obtained from the voltage control block and from power control block through filter impedance. The output of the current controller is fed to SPWM to generate firing pulses to the inverter and the and also the $\mathrm{PV}$ array current is calculated from the inverter current as in equation. (12) and the entire arrangement is depicted in Figure 3.

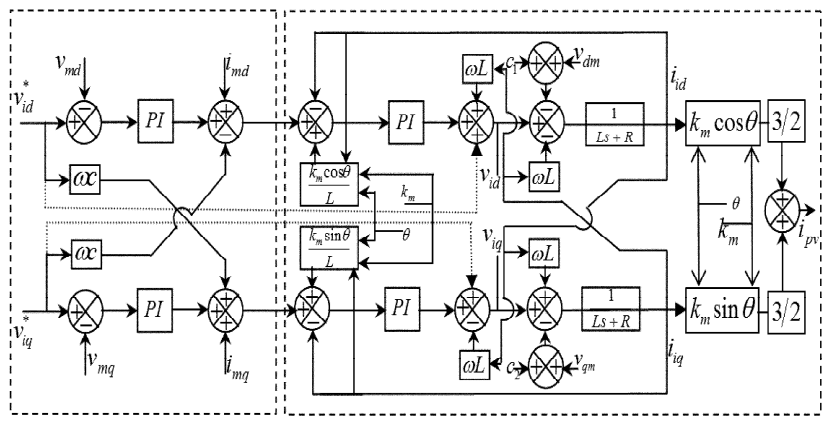

VOLTAGE CONTROL

CURRENT CONTROL

Figure 3. Voltage and Current control scheme. 


\subsubsection{Power Control Block}

In conventional DPC employed for grid connected inverters, the real and reactive power at PCC are taken proportional to $\mathrm{d}$ and $\mathrm{q}$ axis inverter output currents and active and reactive power control is done by hysteresis controllers. In the developed strategy, the measured power at PCC is separated into fundamental and non fundamental components. Here, the hysteresis controller is eliminated and the current reference for current controller is obtained by utilizing the separated fundamental component of power to meet the instantaneous power demand at PCC. The output of the current controller is given to SPWM to generate firing pulses for the inverter. Additionally the function of Active Power Filter (APF) is added to the controller structure. The APF compensates the real and reactive power demand due to non fundamental component with proper estimation of reference current for current control loop. Reactive power requirement of the induction generator changes with change in its magnetizing reactance of the induction generator. Normally magnetizing reactance of the induction generator varies dynamically with respect change of power supplied by the IG. Due to this reason reactive power requirement for the controller design is calculated using instantaneous magnetizing current $i_{m}$ and magnetizing reactance $X_{m}$.

The basic power balance equation for PV array fed wind-driven IG integrated to the grid is given by

$$
P_{i}+P_{w}=P_{L}-P_{g}
$$

Here the load power contains both fundamental (actual power absorbed by the load) and other non-fundamental fundamental (due to nonlinear and power electronics loads) components, these non-fundamental components affect the system power factor and other dynamic performances. Hence the proposed new hybrid controller has been designed to control fundamental and non fundamental components separately. The real power of the load is calculated as $i^{13}$ as indicated in equation. (16).

$$
P_{L}=2\left(v_{g a} i_{L a}+v_{g b} i_{L b}\right)+\left(v_{g a} i_{L b}+v_{L b} i_{L a}\right)
$$

Normally grid voltage contains least value of nonfundamental component and therefore neglected and the fundamental load power is computed as in equation (17) and the non-fundamental component of load power is indicated in equation. (15).

$$
P_{L f}=\frac{2}{3}\left(v_{g d} i_{L f d}+v_{g q} i_{L f q}\right)
$$

$$
P_{\text {Lnf }}=\left(P_{L}-P_{L f}\right)
$$

Similarly the reactive power requirement of the system is computed by using the power balance equation (18). The reactive power drawn by the load contains fundamental and non-fundamental components as indicated in equation (17) and the reactive power consumed by the non-fundamental components affects the system performance, power factor, power generation of IG connected to PCC. The controller is designed to compensate the reactive power requirement through the inverter as indicated in equation. (18). The required reactive power to meet the non linear load and induction generator is supplied by PV sourced inverter.

$$
\begin{gathered}
Q_{L}=\left(Q_{L f}+Q_{n f}\right)=\left(v_{g c} i_{L a}-v_{g a} i_{L c}\right) \\
Q_{i}=\left(Q_{W}+Q_{L}+Q_{g}-Q_{w c}\right)
\end{gathered}
$$

Where $Q_{w c}=\left(v_{g}^{2} \omega_{1} C_{w}\right)$ and

The value of $\omega_{v}$ angular frequency generator terminal voltage for the controller design is obtained through PLL. The power controller structure as indicated in Figure 4.6 is obtained based on the power balance equation (15)-(21).

\subsection{Working of the Proposed Controller Block}

The proposed composite controller comprises of Power controller block as in Figure 4. and voltage and current controlled block as in Figure 3. The current and voltage measured at PCC is fed as input to the power controller. The measured signals are separated into fundamental and non-fundamental components for power computation

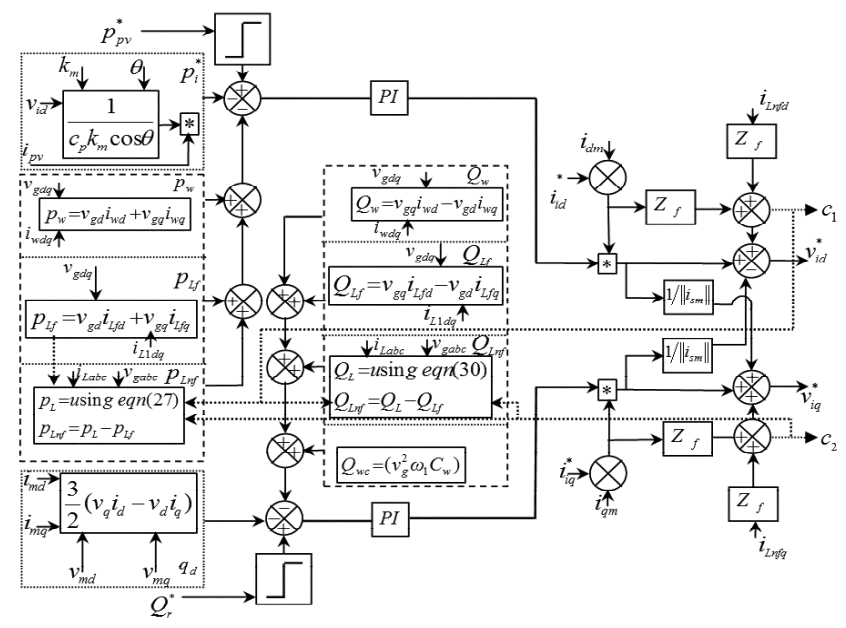

Figure 4. Proposed power control ..scheme 
in the power controller block, these power values are compared with the reference values derived from power balance equation. (15) to generate new PV inverter power $\left(P_{i}^{*}\right)$ reference. This is compared with instantaneous PV power availability. If available array power is greater than the generated reference then the new reference is fixed with the array power and this surplus power from PV is fed to grid if the grid is weak to maintain the power balance. However if grid is not in acceptable state then $P_{i}^{*}$ is fed as input to power controller block.

If the available array power is less than $P_{i}^{*}$ then $P_{i}^{*}$ is set to available array power. Similarly reactive power reference $\left(Q_{i}^{*}\right)$ value of the inverter is computed from the power balance equation. (20) and the value of $\left(Q_{i}^{*}\right)$ is limited by its rated reactive support of the inverter $\left(Q_{i}^{R}\right)$. Out put of this controller generates voltage and current reference values of respective control block using equation. (16). Voltage control block generates current reference value for current controller. The current controller gives the modulating signal for the PWM modulator.

The Figure 5 illustrates inverter control of active and reactive power flows and feasible operating zones of the proposed control. As evident from the phasor diagram power angle $\delta$ is the displacement between the inverter out put voltage $\left(v_{i}\right)$ and grid voltage $\left(v_{g}\right)$. The reactive power demand variation due to the change of load at PCC would result in voltage swell or sag. When there is voltage sag, inverter voltage vector magnitude $\left(v_{i}\right)$ is increased with respect to the grid voltage $\left(v_{g}\right)$ for regulating the voltage by proper exchange of reactive power between inverter to PCC as denoted by $C_{3}$. The circle $C_{3}$ also gives information about feasible reactive power that can be compensated by the inverter. The inverter generates or absorbs reactive power to or from the grid based on the voltage variation at PCC accordingly the inverter current angle varies in III and IV quadrant and limited by area $C_{1}$. At the same

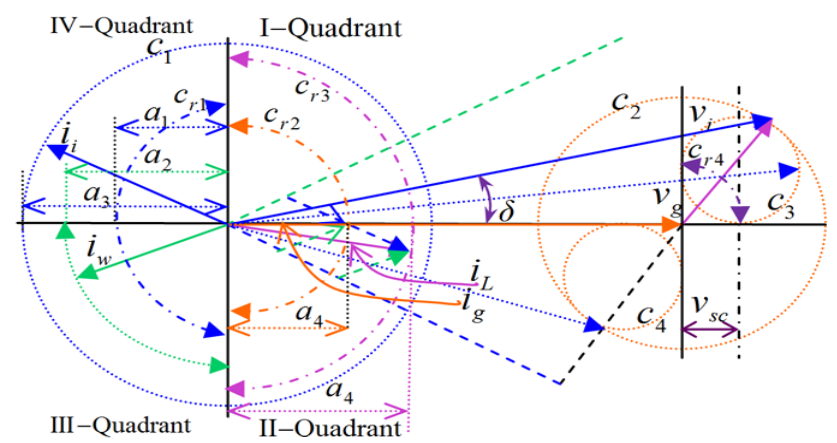

Figure 5. Phasor diagram of proposed control. time induction generator current angle varies only in the III quadrant to ensure operation of IG. Grid current angle may vary in all the four quadrants depending on whether the grid supplies or consumes real or reactive power at PCC and limited by $c_{r 2}$. The variations in consumer load variation may vary in the first and second and quadrants. The inductive and capacitive consumer load demand is limited by the curve $c_{r 3}$. However if the consumer demand exceeds this limit $\left(c_{r 3}\right.$ is greater than $\left.C_{1}\right)$ the inverter fails to deliver. $v_{\text {sc }}$ gives the maximum voltage that can build in IG with self excited capacitance and the reactive power support by self excited capacitance is indicated by $c_{r 4}$.

\section{Analysis of the Proposed Scheme}

To evaluate the controller performance for the hybrid grid connected DG sources, simulations were carried out with conventional power control methods and proposed composite controller using MATLAB\Simulink. The rating and simulation parameters used for the analysis of the scheme are indicated in Table 2. The scheme has been tested with the developed controller for various cases of variation of load demand, variation in irradiation in PV array and wind speed. The effectiveness of the developed controller is also tested for three phase fault at PCC.

Table 2. Proposed system simulation parameters

\begin{tabular}{|c|c|c|c|c|c|}
\hline Components & Parameters & Rating & & arameters & Rating \\
\hline \multirow{6}{*}{ 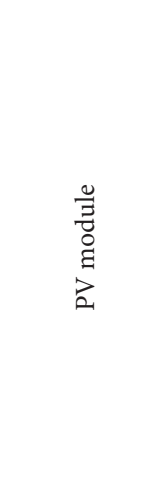 } & $\begin{array}{l}\text { Maximum } \\
\text { power }\end{array}$ & $80 \mathrm{~W}$ & & wer Rating & $2.5 \mathrm{~kW}$ \\
\hline & $\begin{array}{l}\text { Open Circuit } \\
\text { Voltage }\left(\mathrm{V}_{\mathrm{oc}}\right)\end{array}$ & $21.29 \mathrm{~V}$ & & $\begin{array}{l}\text { Voltage } \\
\text { Rating }\end{array}$ & $281.92 V_{\text {Lrms }}$ \\
\hline & $\begin{array}{l}\text { Short Circuit } \\
\text { Current }\left(\mathrm{I}_{\mathrm{sc}}\right)\end{array}$ & $4.72 \mathrm{~A}$ & 苞 & $R_{\mathrm{s}}$ & $0.7384 \Omega$ \\
\hline & $\begin{array}{l}\text { No of Strings } \\
\text { in parallel }\end{array}$ & 11 & : & $L_{\mathrm{s}}$ & $0.003045 \mathrm{H}$ \\
\hline & $\begin{array}{l}\text { No of Strings } \\
\text { in series }\end{array}$ & 30 & 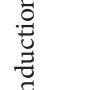 & $R_{\mathrm{r}}^{\prime}$ & $0.7402 \Omega$ \\
\hline & $\begin{array}{l}\text { Variation of } \\
\text { Irradiation }\end{array}$ & $\begin{array}{l}0.47 \mathrm{~kW} / \mathrm{m}^{2} \\
\text { onwards }\end{array}$ & & $L_{\mathrm{r}}^{\prime}$ & $0.003045 \mathrm{H}$ \\
\hline \multirow[t]{2}{*}{ Wind } & $\begin{array}{l}\text { Wind speed } \\
\text { variation }\end{array}$ & 4.9 to $7.68 \mathrm{~m} / \mathrm{s}$ & & $L_{\mathrm{m}}$ & $0.081241 \mathrm{H}$ \\
\hline & Wind Density & $150 \mathrm{~W} / \mathrm{m}^{2}$ & & $C_{\mathrm{w}}$ & $100 \mu \mathrm{F}$ \\
\hline $3 \phi$ Inverter & IGBT module & $200 \mathrm{~V}, 100 \mathrm{~A}$ & & & \\
\hline Grid & \multicolumn{2}{|c|}{$3 \phi, 281.92 V_{\mathrm{Lrms}}, 50 \mathrm{~Hz}$} & \multicolumn{3}{|c|}{$\begin{array}{ll}\text { Dynamic } & 7-11.2 \mathrm{~kW}, \\
\text { Load } & 0.5-1.5 \mathrm{kVar}\end{array}$} \\
\hline Nonlinear load & $2.5 \mathrm{~kW}, 3$ & $\phi$ rectifier load & $\begin{array}{l}\text { Power } \\
\text { Diode }\end{array}$ & \multicolumn{2}{|c|}{$1000 \mathrm{~V}, 25 \mathrm{~A}$} \\
\hline
\end{tabular}




\subsection{Case I (Inclusion of Nonlinear Load at PCC)}

The controller response for incorporating a non linear load of $2.5 \mathrm{~kW}$ at PCC for $\mathrm{t}=1 \mathrm{~s}$ was simulated and the Figure 6. and Figure 7. depicts the fundamental and non fundamental component of inverter current. The nonfundamental component is significantly large as evident in the Figure 7: Measured inverter fundamental current and non-fundamental current with nonlinear load and the algorithm for the controller has been so developed such that power consumed due to the non-fundamental component is compensated by the PV sourced inverter. The real power supplied by PV array fed inverter and wind generator following the same disturbance has been indicated in Figure 8 \& 11 and also Figure $9 \& 12$.

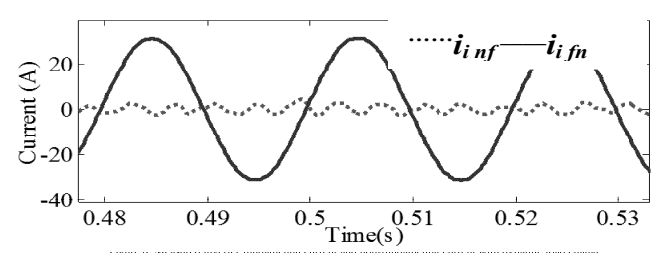

Figure 6. Current during variable Linear loads

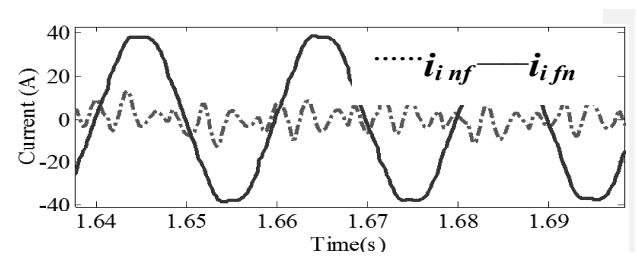

Figure 7. Current during Nonlinear loads.

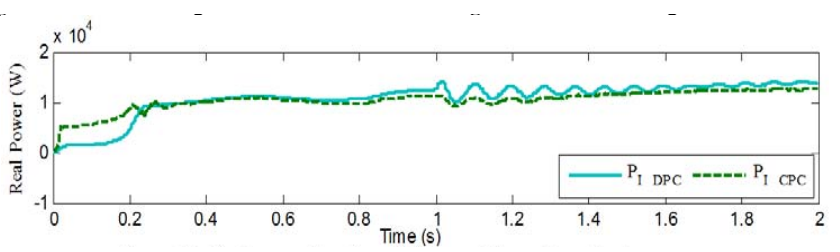

Figure 8. Real power flow from PV array with nonlinear load.

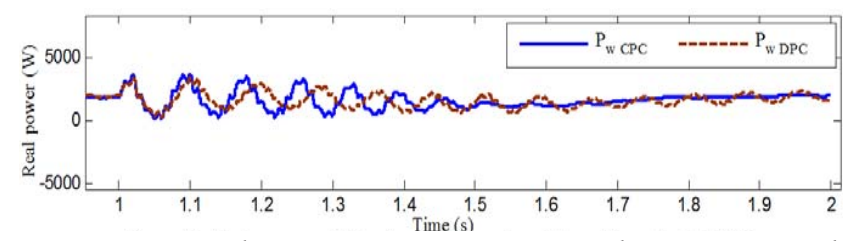

Figure 9. Real power variations in wind generator with nonlinear load PCC.
Following addition of nonlinear load at PCC, the power delivered to the load increases and subsequently there is reduction in the power flow to the grid and this is indicated in Figure 10 With the proposed controller, the reactive power exchange from the grid is maintained at almost zero during the nonlinear load variation for delivering current at UPF at PCC as depicted in Figure 11.

In order to deliver current at UPF at PCC, the current harmonics should meet IEEE 519 Recommended Practice 131

\subsection{Case II (Constant Irradiation and Varying Wind Speed with Fixed Load at PCC)}

Simulations are carried out for varying wind speed $4.775 \mathrm{~m} / \mathrm{s}$ to $7.9567 \mathrm{~m} / \mathrm{s}$ with constant irradiation at $0.6 \mathrm{kWm}^{-2}$ and constant consumer demand of $12.5 \mathrm{~kW}$. It is observed that when DPC is employed, as the wind power increases, the power from PV array fed inverter is reduced and no additional power is fed to the grid. On the other hand with proposed control, the algorithm to the controller is developed such that the PV array is not altered thereby feeding excess power to the grid. (Figure 12.)

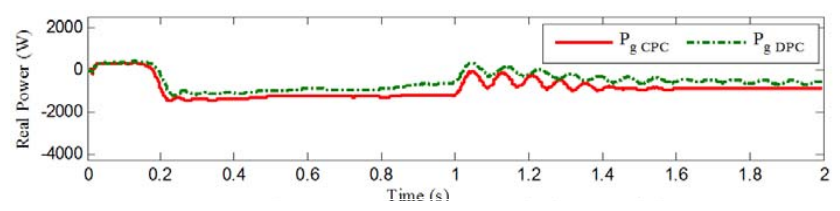

Figure 10. Real Power variations at grid.

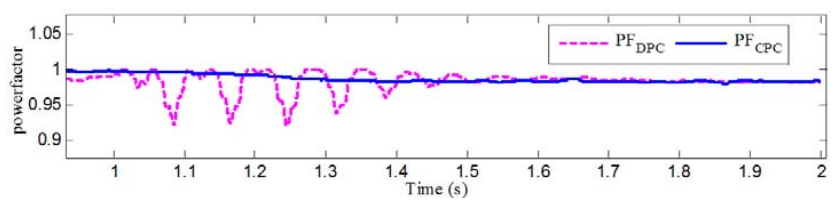

Figure 11. Power factor variation at PCC with nonlinear load variations.

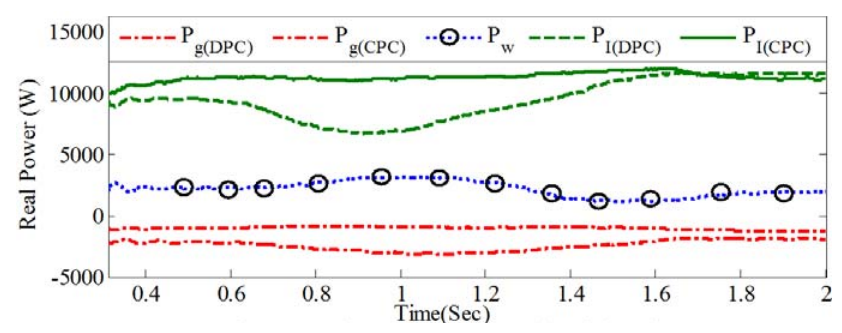

Figure 12. Real power exchange for varying wind speed 


\subsection{Case III (Varying Irradiation, Wind Speed and Consumer Demand)}

Simulations have been carried out for random variations in DG sources and consumer load. When the demand at PCC is increased, if maximum irradiation and wind speed is available, the power balance is achieved at PCC and delivers excess power to the grid. In DPC, the inverter power is altered to meet the demand and does not deliver real power to the grid. The real power variations at the inverter, load and grid for both the controllers has been indicated in Figure 13, and Figure 14.

The reactive power requirement of IG increases with the increase in consumer demand. This is compensated by the inverter if the irradiaton is maximum and has been indicated in the Figure 15.

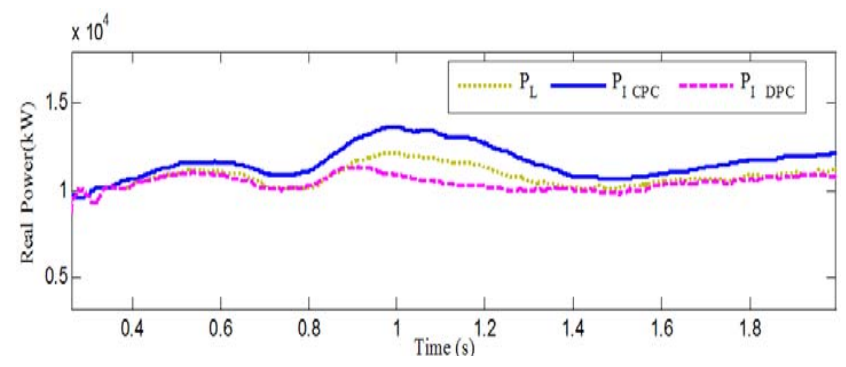

Figure 13. Real power flow variation in inverter load for variations at DG sources and load

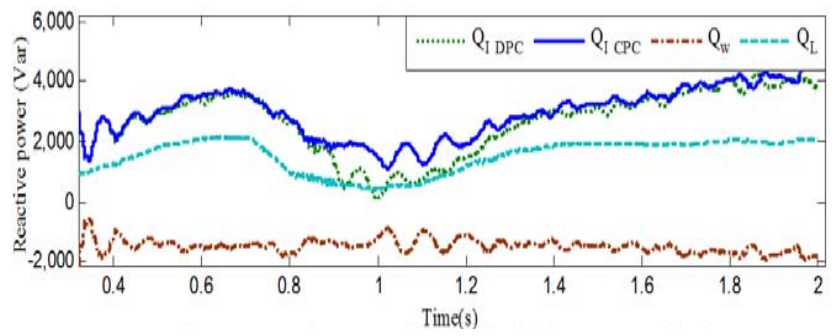

Figure 14. Reactive power flow variation in inverter, IG and load for variation at DG sources and load.

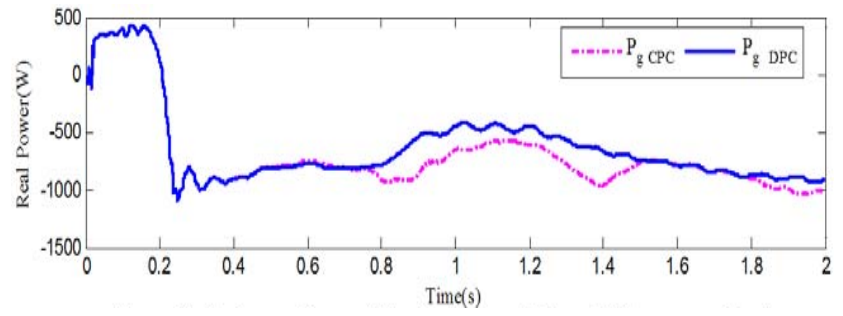

Figure 15. Reactive power flow variation in grid for variation at DG sources and load.

\section{Conclusion}

A dual control strategy comprising of VOC and DPC has been successfully developed for the grid integrated hybrid scheme comprising of PV array and wind driven induction generator. A detailed state space model and analysis is carried out for variations in irradiation, wind speed and consumer demand. The developed model is employed to study the impact of non linear load variation at PCC and results clearly depict the behavior of the controller. The performance of the control strategy for a three phase fault at PCC is also presented. The control of active and reactive power flows of $\mathrm{PV}$ sourced inverter and feasible operating quadrants of the proposed control have been presented. The simulation results of islanded mode of operation for varying customer demand at PCC has been presented. All the analysis taken up in this work has been compared with the conventional DPC control and the improved dynamic performance has been clearly brought out. The developed model can be easily be used to analyse PV-IG scheme of any rating.

\section{References}

1. Carrasco JM. Leopoldo Garcia Franquelo 2006; Power-electronic systems for the grid integration of renewable energy sources: a survey. IEEE Transactions on Industrial Electronics. 2006; 53(4):1002-16.

2. Kaundinya DP, Balachandra P. Grid-connected versus stand-alone energy systems for Decentralized power - a review of literature. Renewable and Sustainable Energy Reviews. 2009; 13:2041-50.

3. Camm E, Edwards C. Reactive compensation systems for large wind farms. Transmission and Distribution Conference and Exposition; 2008. p. 1-5.

4. Karugaba S, Ojo O, Balogun A Influence of non-linear loads on the operation and power flow of induction generators. Conference on Electric Machines and Drives; 2009. p. 1127-34. Doi: 10.1109/ EMDC.2009.5075345.

5. Albuquerque FL, Moraes AJ, Guimaraes GC, Sanhueza SMR, Vaz AR. Photovoltaic solar system connected to the electric power grid operating as active power generator and reactive power compensator. Solar Energy. 2010; 84(7):1310-7. Doi: 10.1016/j.solener.2010.04.011.

6. Zhang $\mathrm{M}$, Ruiqiang $\mathrm{Lv}$, Enyong $\mathrm{Hu}$,Chunhua $\mathrm{Xu}$, Yang $\mathrm{X}$. Research on direct power control strategy. Artificial Intelligence, Management Science and Electronic Commerce (AIMSEC); 2011. p. 7195-7. Doi: 10.1109/ AIMSEC.2011.6010838. 
7. Giglia G, Pucci M, et al. Experimental comparison of three-phase distributed generation systems based on VOC and DPC control techniques. European Conference on Power Electronics and Applications; 2007. p. 1-12. Doi: 10.1109/EPE.2007.4417656.

8. Serpa LA, 2007; Current control strategies for multilevel grid connected inverters. (A dissertation submitted to the swiss federal institute of technology Zurich) Diss. ETH No. 17463. Available from: http://www.pes.ee.ethz.ch/uploads/ tx_thpublications/ Diss_Serpa.pdf.

9. Xu L, Zhi D. et al. Direct power control of grid connected voltage source converters. General Meeting on Power Engineering Society; 2007.

10. Gabe IJ, Palha FFK, Pinheiro H. Grid connected voltage source inverter control during voltage dips. Conference on Industrial Electronics; 2009. p. 4571-6. Doi: 10.1109/ IECON.2009.5414865.

11. Wang L, Yang Y-F, Kuo S-C. Analysis of grid connected induction generators under three-phase balanced conditions. Power Engineering Society Winter Meeting. 2002; 1:413-7. Doi: 10.1109/ PESW.2002.985033.

12. Daniel A, Gounden NA. A Novel hybrid isolated generating system based on PV fed inverter - Assisted wind-driven induction generator. IEEE Transaction on Energy Conversion. 2004 Jun; 19:416-22.

13. Peng FZ, Ott GW, Jr, Adams DJ. Harmonic and reactive power compensation based on the generalized instantaneous reactive power theory for three-phase four-wire systems. IEEE Transactions on Power Electronics. 1998; 13(6):1174-81. Doi: 10.1109/63.728344. 